\title{
Menstrual versus non-menstrual attacks of migraine without aura in women with and without menstrual migraine
}

Kjersti Grøtta Vetvik ${ }^{1,2}$, Jūratė Šaltytė-Benth ${ }^{2,4}$, E. Anne MacGregor ${ }^{3}$, Christofer Lundqvist ${ }^{1,2,4,5}$, Michael Bjørn Russell ${ }^{1,2}$

${ }^{1}$ Head and Neck Research Group, Research Centre, Akershus University hospital, Lørenskog, Norway ${ }^{2}$ Institute of Clinical Medicine, Campus Akershus University Hospital, University of Oslo, Norway

${ }^{3}$ Centre for Neuroscience and Trauma, Blizard Institute, Barts and the London School of Medicine and Dentistry, London, UK

${ }^{4} \mathrm{H} \varnothing \mathrm{KH}$, Research Centre, Akershus University Hospital, Lørenskog, Norway

${ }^{5}$ Department of Neurology, Akershus University Hospital, Lørenskog, Norway

\section{Correspondence}

Kjersti Grøtta Vetvik

Head and Neck Research Group

Research centre

Akershus University Hospital

1478 Lørenskog

Norway

E-mail: kjersti.vetvik@medisin.uio.no

Tel.: +4791398920 


\section{Abstract}

Objectives: To compare clinical characteristics of menstrual and non-menstrual attacks of migraine without aura (MO), prospectively recorded in a headache diary, by women with and without a diagnosis of menstrual migraine without aura (MM) according to the International Classification of Headache Disorders (ICHD).

Material and methods: 237 women from the general population with self-reported migraine in $\geq 50 \%$ of their menstrual periods were interviewed and classified by a physician according to the criteria of the ICHD II. Subsequently, all participants were instructed to complete a prospective headache diary for at least three menstrual cycles. Clinical characteristics of menstrual and non-menstrual attacks of MO were compared by a regression model for repeated measurements.

Results: In total, 123 (52\%) women completed the diary. In the 56 women who were prospectively diagnosed with MM by diary, the menstrual MO-attacks were longer (on average 10.65 hours, $99 \% \mathrm{Cl}$ 3.17-18.12) and more frequently accompanied by severe nausea (OR $2.14,99 \% \mathrm{Cl} 1.20-3.84$ ) than non-menstrual MO-attacks. No significant differences between menstrual and non-menstrual MOattacks were found among women with $\mathrm{MO}$, but no $\mathrm{MM}$.

Conclusion: In women from the general population, menstrual MO-attacks differ from nonmenstrual attacks only in women who fulfil the ICHD criteria for MM. 


\section{Introduction}

About $20 \%$ of female migraineurs from the general population suffer from menstrual migraine without aura $(\mathrm{MM})(1,2)$, defined as attacks of migraine without aura $(\mathrm{MO})$ occurring on day $1 \pm 2$ (i.e. days -2 to +3 ) of menstruation in at least two out of three menstrual cycles (3). MM is subdivided into pure menstrual migraine, including women with attacks of $\mathrm{MO}$ exclusively at menstruation, and menstrually-related migraine, where attacks also occur at other times of the cycle. The diagnostic criteria are placed in the appendix of the International Classification of Headache Disorders (ICHD) II and III beta and are primarily considered as research criteria that need further validation before possible inclusion into the main body of the classification $(3,4)$.

It is debated whether MM is a distinct clinical entity, since previous studies report divergent findings concerning differences in characteristics of menstrual and non-menstrual migraine attacks. Analyses including women with a diagnosis of MM indicate that menstrual attacks are more painful, longer lasting, more disabling and less responsive to treatment (5-9). Most studies reporting that there is no difference compare menstrual versus non-menstrual attacks in all women with migraine, without considering the required frequency of attacks related to menstruation, and so are likely to include women whose menstrual attacks are a chance occurrence rather than there being a true association (10-12). Separate and comparative analyses between female migraineurs with and without a prospectively confirmed diagnosis of MM have to our knowledge not been published previously.

The aim of the present study was to compare the clinical characteristics of menstrual and nonmenstrual MO-attacks in women with and without a diary-confirmed diagnosis of MM.

\section{Material and methods}

Screening, population, and clinical interviews

A random sample of 5000 women, aged 30-34 years, from the general population received a mailed screening questionnaire about headache, migraine and its relation to menstruation. The response rate to the questionnaire was $73 \%$. Women with self-reported migraine in $\geq 50 \%$ of their menstruations and $<180$ headache days during the preceding year were invited to a clinical interview and examination conducted by a headache specialist (KGV). At interview time the participants were $36-40$ years old. Of 360 women meeting the inclusion criteria, 52 were not eligible due to emigration $(n=4)$, insufficient Norwegian language skills $(n=9)$, and no reply to five telephone calls or more $(n=39)$. Among the 308 eligible women, 237 (77\%) participated in the interview. Seventy-one declined to participate due to lack of time, no interest, or acute illness. Women, who were not able to come to the clinic, were interviewed by telephone $(87 / 237)$. The interview focused 
on headache diagnoses and characteristics. Subsequently all women were asked to complete a prospective headache- and menstruation paper-pencil diary for three months. A more exhaustive description of the screening method and interviews is published elsewhere $(1,13)$.

When a headache occurred, the women recorded: time of onset and end of headache, aura symptoms, pain quality and location, severity on Numeric Rating Scale 0-10 (NRS; 0=no pain, 10= most severe pain), aggravation by routine physical activity, medical treatment (type and dose) and sick leave. The associated symptoms (i.e. nausea, photo- and phonophobia) were graded 0-3; 0=no symptoms, $1=$ =mild, $2=$ =moderate and $3=$ severe. In addition, women were asked to record each day of uterine bleeding.

The women were allowed to take their usual medication including migraine prophylaxis and hormonal contraception. The diaries were returned by mail in a stamped pre-addressed envelope. If a diary was not returned after three months, one reminder was issued.

\section{Data entry and analysis of headache diaries}

The diaries were reviewed by two investigators (KGV and MBR) and the diary database was constructed by one investigator (KGV) in order to ensure consistency. In cases with missing information about the exact timing of menstruation, the subject was contacted by telephone to elaborate the information. When a migraine attack lasted more than one day, it was considered as a single multiday attack, unless an interval of $\geq 48$ hours pain-free separated the headaches. This definition was used since most of the attacks were treated with symptomatic drugs and migraine occurring within 48 hours is considered as relapse of migraine in randomized controlled drug trials (14). When all but one ICHD criterion for MO were fulfilled, or the duration was $<4$ hours, the attack was considered as $\mathrm{MO}$ if symptomatic treatment was used. A diagnosis of MM required at least two $\mathrm{MO}$ attacks with onset on day $1 \pm 2$ of the menstrual cycle during three consecutive cycles. If an attack started outside the defined period (day $1 \pm 2$ ), it was considered as a non-menstrual attack. In order to make comparisons between the same headache types, i.e. $\mathrm{MO}$, attacks of migraine with aura and tension-type headache were excluded. Status migrainosus was defined as debilitating attacks lasting for more than 72 hours with remissions up to 12 hours because of medication or sleep (3). 


\section{Statistics}

Continuous demographic and clinical characteristics were presented as means and standard deviations (SDs), while frequencies and percentages were used to describe dichotomous characteristics. Independent samples t-test or Fisher's exact test was used to compare the characteristics between women with and without MM. Three continuous (pain score, duration and number of doses), three graded categorical (nausea, photo-and phonophobia) and two dichotomous (treatment and sick leave) parameters were recorded for each migraine attack, resulting in repeated measurements for each woman. Differences in menstrual and non-menstrual migraine attacks were assessed by a regression model for repeated measurements adjusting for intra-individual correlations; linear for continuous, ordinal for categorical and logistic for dichotomous parameters. Intra-class correlation coefficient (ICC) was calculated to assess the proportion of variance occurring within-women. Regression models contained fixed effect for variable categorizing the attacks into menstrual and non-menstrual attacks in women with and without a diagnosis of $\mathrm{MM}$, with nonmenstrual attacks in women with a diagnosis of MM as reference category. Random effect for intercept, accounting for within-woman variability, was included into the model. Results were presented as coefficients or odds ratios (ORs) with 99\% confidence intervals (Cls). The coefficient from a linear model represents estimated average difference between the reference and three other categories (i.e. menstrual and non-menstrual attacks in women without $\mathrm{MM}$ and menstrual attacks in women with MM). Ordinal and logistic regression models estimate the odds for presence of a specific symptom in a certain category with respect to the reference category. The ratio of the generalized $\chi^{2}$ statistic and its degrees of freedom was nearly one in the logistic models indicating no overdispersion in the data. Baseline factors differing between the groups (migraine days/cycle, migraine attacks/cycle and employment status) were included into the models with significant associations one at a time to test if the associations were modified. In addition, the models were adjusted for progestin-only and combined hormonal contraception. None of the associations were affected by these adjustments.

All analyses were performed in SPSS v20 and SAS v9.3 (MIXED and GLIMMIX procedures). A significance level of 0.01 was chosen to partially address for multiple tests.

\section{Ethics}

The study was approved by the Regional Committee for Medical Research Ethics and the Norwegian Data Protection Authorities. The participants received written and verbal information about the project and inclusion was based on informed consent. No reimbursement for participation was given. 


\section{Results}

Among the 237 women who were interviewed, 123 (52\%) returned the diary. Of these, 42 were excluded from analysis due to oligo-/amenorrhoea $(n=36)$, exclusively tension-type headache $(n=4)$ or incomplete diaries ( $n=2)$. Thus, diaries from 81 women were analysed (figure 1). Women who were interviewed face-to-face, were significantly more likely to return the diary compared to those interviewed by telephone ( $\mathrm{OR}=2.87,95 \% \mathrm{Cl} 1.66-4.96)$. There were no significant differences between women who returned and those who did not return the diary with respect to clinical MMdiagnosis or migraine frequency (13).

A total of 56 women fulfilled the diagnostic criteria for MM in the diary, while 25 women had MO, but did not fulfil the criteria for MM. The 81 women recorded a total of 261 menstrual cycles and 435 MO-attacks (908 MO-days) during the 7202 diary-days. Women with MM recorded 167 menstrual and 191 non-menstrual MO-attacks, while the respective numbers in women without MM were 19 and 58. Mean menstrual cycle length in all 81 women was $28.4 \pm 4.5$ days, with no difference between the groups.

\section{Demographic and clinical characteristics of women with and without MM}

Table 1 shows demographic and clinical characteristics of women with and without a diary-confirmed diagnosis of MM. Women with MM had a higher migraine frequency recording on average 2.0 migraine attacks per cycle, compared to 1.4 in women without $\mathrm{MM}(\mathrm{P}=0.006)$. There were no differences between women with and without MM with respect to age at menarche or migraine onset, use of hormonal contraception or migraine prophylaxis, self-reported menstrual pain or a diagnosis of endometriosis. The levonorgestrel-Intrauterine system was the most frequently used progestin-only contraception, used by seven women with MM and one woman without MM. One woman in each group used the Desogestrel-only pill. Among users of combined hormonal contraception, one woman (with $\mathrm{MM}$ ) used the vaginal ring, while the remaining used the combined contraceptive pill. All women used the combined hormonal contraceptives in a cyclic regimen. The proportions of users of the subtypes of contraception did not differ between women with and without MM (table 1). 


\section{Characteristics of menstrual and non-menstrual MO-attacks}

Clinical characteristics of menstrual and non-menstrual MO-attacks in women with and without a diary-diagnosis of MM are presented in Table 2. Intra-class correlation (ICC) was varying between $25 \%$ and $52 \%$, demonstrating a considerable variation of $\mathrm{MO}$-attacks from time to time within the same individual.

\section{Women with a diary diagnosis of MM}

Menstrual MO-attacks lasted significantly longer than non-menstrual attacks and were more often accompanied by severe nausea in women with MM (table 2). A non-significant trend towards more occurrence of status migrainosus was observed (OR 4.34, 99\% $\mathrm{Cl}$ 0.94-20.09) and the menstrual attacks tended to be more painful $(0.37$ on a $0-10$ score, $99 \% \mathrm{Cl}-0.08-0.81)$. No difference in sick leave was observed between the menstrual and non-menstrual attacks (OR 1.41, 99\% Cl 0.55- 3.58).

Menstrual migraine attacks were treated with significantly more doses of symptomatic drugs per attack and multiple agent treatment strategies were more often recorded (Table 3). The proportion of attacks treated with triptans did not differ between menstrual and non-menstrual attacks (table 3 ), but the number of triptan doses per attack was significantly higher in the menstrual attacks (mean difference $1.37,99 \% \mathrm{Cl} 0.50-2.24)$. A non-significant trend towards more use of NSAIDs was additionally observed in the menstrual attacks (table 3 ).

\section{Women with MO, without a diary diagnosis of MM}

The confidence intervals indicate that there were no significant clinical differences between menstrual and non-menstrual attacks in women not fulfilling the criteria for MM (Table 2). Nor did treatment differ between menstrual and non-menstrual attacks in this group (table 3).

\section{Additional analyses using other diagnostic methods}

We also performed the analyses on women classified according to their interview-diagnosis of MM $(n=81)$, disregarding the diary-diagnoses. Additionally we performed a third analysis including only women with the same MM-diagnosis according to both interview and diaries $(n=66)$. In both analyses, the menstrual attacks remained significantly longer, required more doses of symptomatic treatment and were more often associated with nausea. There were no differences in characteristics of the menstrual attacks between the women with pure menstrual migraine and menstrually-related migraine. 


\section{Discussion}

Our main finding is that menstrual attacks of $\mathrm{MO}$ are significantly longer and more often associated with severe nausea than non-menstrual attacks in women who fulfil the ICHD-criteria for MM. We found no differences between menstrual and non-menstrual attacks in women with $\mathrm{MO}$, but no diary-confirmed diagnosis of MM.

Our results may thus explain the divergent findings between previous studies, as the differences most likely depend on the women's diagnosis of MM. Among the previous diary-studies, only four compare characteristics of menstrual and non-menstrual attacks in women with a diagnosis of MM (5-8). These studies consistently find that menstrual attacks are more disabling, longer lasting, and more difficult to treat, while the results concerning pain intensity and associated symptoms are conflicting. We observed a non-significant trend towards more painful attacks, but the magnitude of difference was small and probably not clinically relevant, i.e. 0.37 on a 0-11 point scale. Among the studies comparing menstrual and non-menstrual attacks among all female migraineurs, without restricting their sample to women diagnosed with $\mathrm{MM}$, the results vary from no difference to similar results as ours (10-12). In two of these studies, the proportions of menstrual attacks of all migraine attacks were $19 \%$ and $23 \%(11,12)$. In our population of women with $\mathrm{MM}$ and in a previous study of women with MM (8), menstrual attacks represented $47 \%(167 / 358)$ and $59 \%$ of all migraine attacks. This may indicate that some of the studies of all female migraineurs included few women with a diagnosis of MM.

Several randomized controlled trials (RCT) and post hoc analyses of RCTs report that triptans are superior to placebo in the acute treatment of menstrual migraine attacks, both in women with and without a confirmed diagnosis of $\operatorname{MM}(11,15,16)$. However, when responses to treatment are compared between menstrual and non-menstrual attacks in women diagnosed with MM, significant lower 2-h pain-free responses and higher recurrence rates within 24 hours in menstrual attacks are reported $(5,6,8)$. Our study was not designed to evaluate treatment efficacy, but the fact that the menstrual attacks were on average nearly 11 hours longer and required more doses of triptans, may indicate a higher relapse rate and/or lower efficacy of the initial dose in the menstrual attacks of women with MM. In addition we observed a non-significant trend towards more use of NSAIDs or multiple-agent strategies in the menstrual attacks, which could be explained by the general knowledge that NSAIDs are effective against comorbid menstrual pain. However, according to our interview data, women with MM reported modest menstrual pain (on average 3.4 on a -10 point scale) and there were no significant differences among women with and without the MM-diagnosis (Table 1). Since the menstrual attacks in women with MM were treated with more symptomatic 
drugs, the real clinical differences between the attacks may be even more marked than our results suggest.

\section{Strengths and limitations}

This is the first study from the general population comparing menstrual and non-menstrual attacks in women with a diagnosis of MM using a headache- and menstruation diary. The previous studies were conducted in clinic populations and questions have been raised concerning the possible influence of selection bias (10). Our study is, to our knowledge, the first study which assesses attacks in female migraineurs with and without a diagnosis of MM. The women recorded on average 3.2 menstrual cycles, which is required in order to establish the diagnosis. Several of the previous studies only included 1-2 cycles. Moreover, none of the participants in our study had chronic migraine. Studies including women with very frequent migraine are more likely to include women with menstrual attacks by chance. We excluded migraine with aura attacks, since the headache following migraine aura does not necessarily have pain and accompanying symptoms similar to that of $\mathrm{MO}(2,17,18)$.

Our statistical methods used to assess the differences between the attacks adjust the estimates for correlations due to repeated measures. In addition, the methods used minimize effects of missing data by including all available information into the model. Due to multiple tests, we also chose a conservative significance level $(<0.01)$ to reduce the risk of mass significance by chance.

Only $52 \%$ of the participants returned the diary, which might introduce a bias in our results. However, there were no difference between women who returned the diary and those who did not regarding migraine diagnoses, migraine frequency, educational level or income. The only difference noticed, was the higher return rate of diaries among women who were interviewed face-to-face compared to those interviewed by telephone. This might indicate that women who invested time in order to come to the hospital for a face-to-face interview were more motivated and interested in participation.

All women in this study were invited to the initial clinical interview based on their self-report of migraine in at least half of menstruations six years previously. Thus, the 25 women who were not diagnosed with MM by diary are not representative for all female migraineurs due to the selfreported association between migraine and menstruation. The six years delay between screening and interview did not influence the presented results, since we only analysed data from diaries and interviews that were collected in close temporal relation. Since we restricted inclusion to women aged 36-40 years our results may not be representative of older or younger women.

In our sample, we could not identify differences between menstrual and non-menstrual attacks in the 25 women with MO attacks, but no MM. Their attacks represented less than one fifth of all MO- 
attacks analysed and we cannot exclude the possibility that the analyses of the women without MM lacked statistical power. The differences observed between women with and without MM should however be considered in future studies of $\mathrm{MM}$, and stresses the importance of separate analyses of the two groups.

The use of migraine prophylaxis or hormonal contraception could have influenced on our results, but the proportion of users was equally distributed between the groups.

\section{Conclusion}

In women from the general population who fulfil the ICHD criteria for MM, menstrual MO- attacks are longer lasting, and more often associated with severe nausea than non-menstrual attacks. However, in women with migraine, but no MM, menstrual attacks do not differ significantly from non-menstrual migraine attacks.

\section{Funding}

This study was supported by grants from the South-Eastern Norway Regional Health Authority (grant number 2013001), Akershus University Hospital (grant number 2629014) and Institute of Clinical Medicine, University of Oslo.

\section{Conflict of Interest Statement}

None declared

\section{Clinical implications}

- In women with a diagnosis of menstrual migraine without aura, menstrual attacks were longer lasting, more often associated with nausea, and treated with more doses of symptomatic drugs than non-menstrual migraine attacks.

- In women with migraine without aura, not fulfilling the diagnostic criteria for menstrual migraine, no differences between menstrual and non-menstrual attack were found. 


\section{Table and figures}

Figure 1. Flow chart of the study

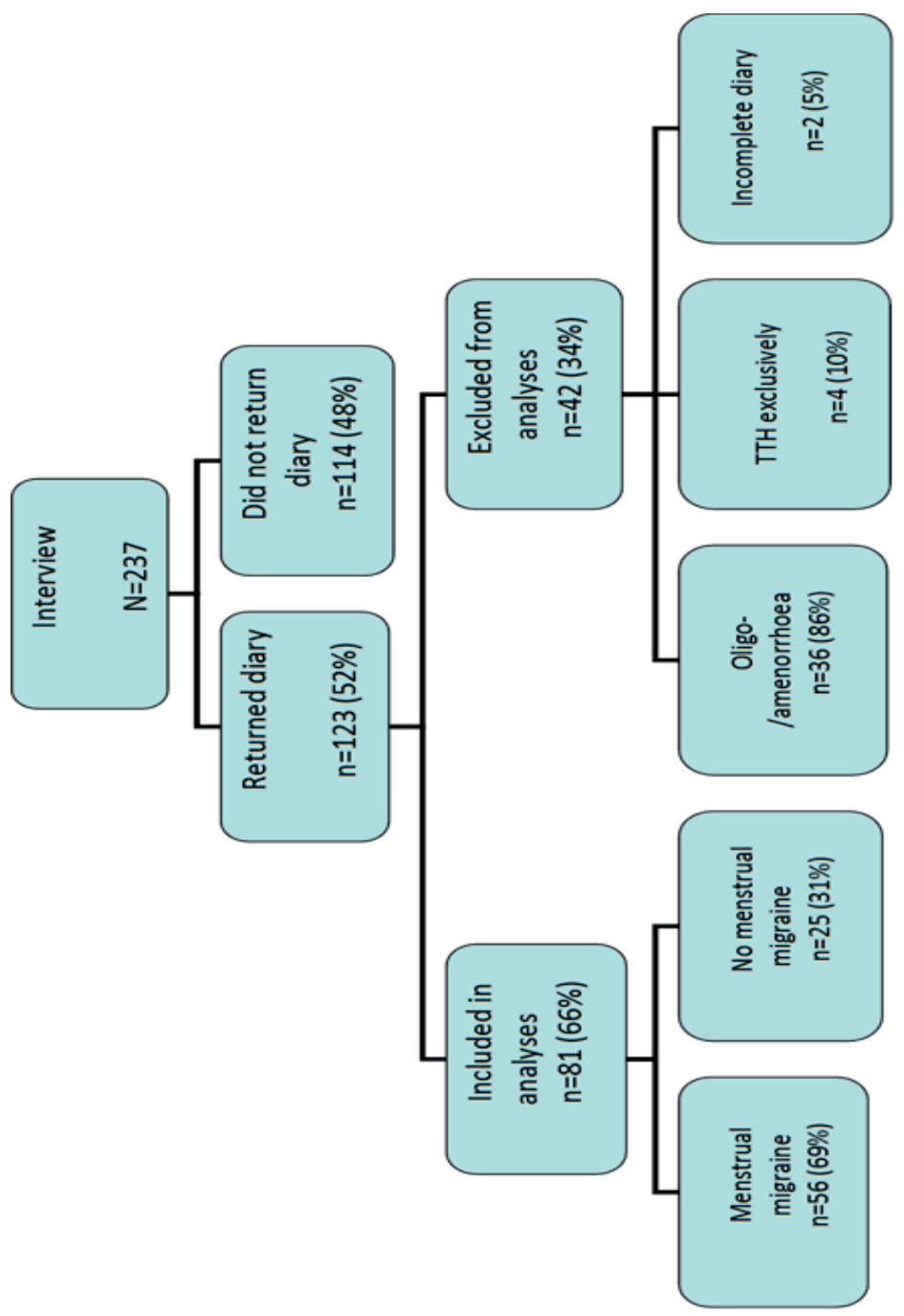


Table 1. Demographic and clinical characteristics of the participants

\begin{tabular}{|c|c|c|c|}
\hline & $\begin{array}{c}\text { MM- } \\
\text { diagnosis } \\
(n=56)\end{array}$ & $\begin{array}{l}\text { No MM- } \\
\text { diagnosis } \\
(n=25)\end{array}$ & p-value \\
\hline Continuous variables $^{1}$ & \multicolumn{2}{|c|}{ Mean (SD) } & \\
\hline Age (years) & $38.3(1.3)$ & $38.6(1.3)$ & 0.35 \\
\hline Age at migraine onset (years) & $19.0(7.5)$ & $21.0(7.1)$ & 0.27 \\
\hline Age at menarche (years) & $12.9(1.4)$ & $13.1(1.8)$ & 0.58 \\
\hline Cycle length (days) & $28.5(5.0)$ & $28.2(3.4)$ & 0.71 \\
\hline Migraine days/cycle & $4.4(2.5)$ & $2.7(2.3)$ & 0.007 \\
\hline Migraine attacks/cycle & $2.0(0.9)$ & $1.4(1.0)$ & 0.006 \\
\hline Menstrual pain (0-10) & $3.4(2.5)$ & $3.1(2.9)$ & 0.71 \\
\hline Dichotomous variables ${ }^{2}$ & \multicolumn{2}{|c|}{$\%(n)$} & \\
\hline Migraine prophylaxis & $8.9(5)$ & $0(0)$ & 0.32 \\
\hline Hormonal contraception & $26.8(15)$ & $24.0(6)$ & 1.00 \\
\hline Combined hormonal contraception & $12.5(7)$ & $16.0(4)$ & 0.73 \\
\hline Progestin-only contraception & $14.3(8)$ & $8.0(2)$ & 0.72 \\
\hline Self-reported menorrhagia & $23.2(13)$ & $32.0(8)$ & 0.42 \\
\hline Endometriosis & $3.6(2)$ & $8.0(2)$ & 0.58 \\
\hline Higher educational level \% (n)* & $63.6(35)$ & $62.5(15)$ & 1.00 \\
\hline Income $>400000$ (NOK/year)** & $50.9(28)$ & $40.9(9)$ & 0.46 \\
\hline Employed & $91.1(51)$ & $72.0(18)$ & 0.04 \\
\hline Married/living with a partner*** & $83.3(45)$ & $66.7(16)$ & 0.14 \\
\hline
\end{tabular}

${ }^{1}$ Independent t-test. ${ }^{2}$ Fisher's exact test. ${ }^{*} 2$ missing values, $* * 4$ missing values, ${ }^{* * *} 3$ missing values. 
Table 2. Clinical characteristics of menstrual and non-menstrual attacks of migraine without aura

\begin{tabular}{|c|c|c|c|c|c|c|c|}
\hline Diagnosis & Continuous variables $^{1}$ & $\mathbf{n}$ & \multicolumn{4}{|c|}{ Mean (SD) } & Coefficient $(99 \% \mathrm{Cl})$ \\
\hline $\begin{array}{l}\text { Menstrual } \\
\text { migraine }\end{array}$ & $\begin{array}{l}\text { Pain score }(0-10) \\
\text { Non-menstrual attack- ref } \\
\text { Menstrual attack }\end{array}$ & $\begin{array}{l}191 \\
166\end{array}$ & \multicolumn{4}{|c|}{$\begin{array}{l}6.15(1.85) \\
6.49(1.80)\end{array}$} & $\begin{array}{c}0 \\
0.37(-0.08-0.81)\end{array}$ \\
\hline $\begin{array}{l}\text { No menstrual } \\
\text { migraine }\end{array}$ & $\begin{array}{l}\text { Non-menstrual attack } \\
\text { Menstrual attack }\end{array}$ & $\begin{array}{l}58 \\
19\end{array}$ & \multicolumn{4}{|c|}{$5.86(1.88)$} & $\begin{array}{l}-0.29(-1.22-0.63) \\
-0.42(-1.62-0.79)\end{array}$ \\
\hline $\begin{array}{l}\text { Menstrual } \\
\text { migraine }\end{array}$ & $\begin{array}{l}\text { Duration of attack (hours) } \\
\text { Non-menstrual attack-ref } \\
\text { Menstrual attack }\end{array}$ & $\begin{array}{l}175 \\
162\end{array}$ & \multicolumn{4}{|c|}{$\begin{array}{l}20.15(23.98) \\
30.39(32.28)\end{array}$} & $\begin{array}{c}0 \\
10.65(3.17-18.12)^{*}\end{array}$ \\
\hline $\begin{array}{l}\text { No menstrual } \\
\text { migraine }\end{array}$ & $\begin{array}{l}\text { Non-menstrual attack } \\
\text { Menstrual attack }\end{array}$ & $\begin{array}{l}53 \\
18\end{array}$ & \multicolumn{4}{|c|}{$\begin{array}{l}26.57(33.55) \\
22.28(25.90)\end{array}$} & $\begin{array}{c}6.79(-8.01-21.60) \\
3.84(-15.86-23.54)\end{array}$ \\
\hline \multirow[t]{2}{*}{ Diagnosis } & \multirow[t]{2}{*}{ Ordinal variables $^{2}$} & \multirow[t]{2}{*}{$n$} & \multicolumn{4}{|c|}{ Severity grade $(\%)^{3}$} & OR (99\% CI) \\
\hline & & & 0 & 1 & 2 & 3 & \\
\hline $\begin{array}{l}\text { Menstrual } \\
\text { migraine }\end{array}$ & $\begin{array}{l}\text { Nausea } \\
\text { Non-menstrual attack-ref } \\
\text { Menstrual attack }\end{array}$ & $\begin{array}{l}190 \\
167\end{array}$ & $\begin{array}{l}53 \\
38\end{array}$ & $\begin{array}{l}27 \\
34\end{array}$ & $\begin{array}{l}16 \\
20\end{array}$ & $\begin{array}{l}4 \\
8\end{array}$ & $\begin{array}{c}1 \\
2.14(1.20-3.84)^{*}\end{array}$ \\
\hline $\begin{array}{l}\text { No menstrual } \\
\text { migraine }\end{array}$ & $\begin{array}{l}\text { Non-menstrual attack } \\
\text { Menstrual attack }\end{array}$ & $\begin{array}{l}57 \\
19\end{array}$ & $\begin{array}{l}47 \\
47\end{array}$ & $\begin{array}{l}28 \\
32\end{array}$ & $\begin{array}{l}18 \\
21\end{array}$ & $\begin{array}{l}7 \\
0\end{array}$ & $\begin{array}{l}1.75(0.46-6.68) \\
1.58(0.29-8.51)\end{array}$ \\
\hline $\begin{array}{l}\text { Menstrual } \\
\text { migraine }\end{array}$ & $\begin{array}{l}\text { Photophobia } \\
\text { Non-menstrual attack-ref } \\
\text { Menstrual attack }\end{array}$ & $\begin{array}{l}190 \\
167\end{array}$ & $\begin{array}{l}40 \\
37\end{array}$ & $\begin{array}{l}35 \\
30\end{array}$ & $\begin{array}{l}16 \\
25\end{array}$ & $\begin{array}{l}9 \\
8\end{array}$ & $\begin{array}{c}1 \\
1.42(0.77-2.60)\end{array}$ \\
\hline $\begin{array}{l}\text { No menstrual } \\
\text { migraine }\end{array}$ & $\begin{array}{l}\text { Non-menstrual attack } \\
\text { Menstrual attack }\end{array}$ & $\begin{array}{l}55 \\
18\end{array}$ & $\begin{array}{l}33 \\
50\end{array}$ & $\begin{array}{l}44 \\
33\end{array}$ & $\begin{array}{l}11 \\
11\end{array}$ & $\begin{array}{c}11 \\
6\end{array}$ & $\begin{array}{l}1.81(0.32-9.35) \\
0.81(0.11-5.90)\end{array}$ \\
\hline $\begin{array}{l}\text { Menstrual } \\
\text { migraine }\end{array}$ & $\begin{array}{l}\text { Phonophobia } \\
\text { Non-menstrual attack-ref } \\
\text { Menstrual attack }\end{array}$ & $\begin{array}{l}190 \\
167\end{array}$ & $\begin{array}{l}40 \\
38\end{array}$ & $\begin{array}{l}37 \\
31\end{array}$ & $\begin{array}{l}17 \\
22\end{array}$ & $\begin{array}{l}6 \\
9\end{array}$ & $\begin{array}{c}1 \\
1.48(0.79-2.76)\end{array}$ \\
\hline $\begin{array}{l}\text { No menstrual } \\
\text { migraine }\end{array}$ & $\begin{array}{l}\text { Non-menstrual attack } \\
\text { Menstrual attack }\end{array}$ & $\begin{array}{l}52 \\
18\end{array}$ & $\begin{array}{l}55 \\
67\end{array}$ & $\begin{array}{l}35 \\
22\end{array}$ & $\begin{array}{l}6 \\
6\end{array}$ & $\begin{array}{l}4 \\
6\end{array}$ & $\begin{array}{l}0.35(0.04-3.15) \\
0.80(0.13-4.70)\end{array}$ \\
\hline $\begin{array}{l}{ }^{1} \text { Linear mixed } r \\
\text { intercept }(\mathrm{SAS} \\
2=\text { moderate an } \\
{ }^{*} \mathrm{p}<0.01 \\
\mathrm{MM}=\text { menstrual } \\
\mathrm{OR}=\text { odds ratio. } \\
\text { Number of mig } \\
\text { Number of mig }\end{array}$ & $\begin{array}{l}\text { odel with random intercept (SAS } \\
\text { IMMIX). }{ }^{3} \text { Severity grade } \% \text { : perc } \\
3=\text { severe. } \\
\text { nigraine without aura. } n=\text { numbe } \\
\text { l=confidence interval. } \\
\text { ine without aura attacks in wom } \\
\text { ine without aura attacks in wom }\end{array}$ & attacl & $w$ & $7 \mathrm{n}$ & & s. & $\begin{array}{l}\text { chical data with random } \\
\text { toms, 1=mild, } \\
\text { standard deviation. } \\
\text { non-menstrual. }\end{array}$ \\
\hline
\end{tabular}


Table 3. Pharmacological management of migraine without aura

\begin{tabular}{|c|c|c|c|c|}
\hline Diagnosis & $\begin{array}{l}\text { Dichotomous variables }^{1} \\
\text { Symptomatic treatment used }\end{array}$ & n & $\%(n)$ & OR $(99 \% \mathrm{Cl})$ \\
\hline $\begin{array}{l}\text { Menstrual } \\
\text { migraine }\end{array}$ & $\begin{array}{l}\text { Non-menstrual attack-ref } \\
\text { Menstrual attack }\end{array}$ & $\begin{array}{l}191 \\
167\end{array}$ & $\begin{array}{l}85.3(162) \\
92.8(155)\end{array}$ & $2.62(0.91-7.54)$ \\
\hline $\begin{array}{l}\text { No menstrual } \\
\text { migraine }\end{array}$ & $\begin{array}{l}\text { Non-menstrual attack } \\
\text { Menstrual attack } \\
\text { Paracetamol }\end{array}$ & $\begin{array}{l}58 \\
19\end{array}$ & $\begin{array}{l}67.2(39) \\
78.9(15)\end{array}$ & $\begin{array}{l}0.49(0.12-2.02) \\
0.79(0.11-5.61)\end{array}$ \\
\hline $\begin{array}{l}\text { Menstrual } \\
\text { migraine }\end{array}$ & $\begin{array}{l}\text { Non-menstrual attack-ref } \\
\text { Menstrual attack }\end{array}$ & $\begin{array}{l}191 \\
167\end{array}$ & $\begin{array}{l}31.4(60) \\
33.5(56)\end{array}$ & $\begin{array}{c}1 \\
1.41(0.61-3.26)\end{array}$ \\
\hline $\begin{array}{l}\text { No menstrual } \\
\text { migraine }\end{array}$ & $\begin{array}{l}\text { Non-menstrual attack } \\
\text { Menstrual attack } \\
\text { NSAIDs }\end{array}$ & $\begin{array}{l}58 \\
19\end{array}$ & $\begin{array}{l}48.3(28) \\
63.2(12)\end{array}$ & $\begin{array}{l}4.32(0.90-20.83) \\
6.14(0.84-44.61)\end{array}$ \\
\hline $\begin{array}{l}\text { Menstrual } \\
\text { migraine }\end{array}$ & $\begin{array}{l}\text { Non-menstrual attack-ref } \\
\text { Menstrual attack }\end{array}$ & $\begin{array}{l}191 \\
167\end{array}$ & $\begin{array}{l}46.1(88) \\
59.3(99)\end{array}$ & $\begin{array}{c}1 \\
2.04(0.99-4.18)\end{array}$ \\
\hline $\begin{array}{l}\text { No menstrual } \\
\text { migraine }\end{array}$ & $\begin{array}{l}\text { Non-menstrual attack } \\
\text { Menstrual attack } \\
\text { Triptans }\end{array}$ & $\begin{array}{l}58 \\
19\end{array}$ & $\begin{array}{l}34.5(20) \\
31.6(6)\end{array}$ & $\begin{array}{l}0.62(0.14-2.69) \\
0.79(0.12-5.38)\end{array}$ \\
\hline $\begin{array}{l}\text { Menstrual } \\
\text { migraine }\end{array}$ & $\begin{array}{l}\text { Non-menstrual attack-ref } \\
\text { Menstrual attack }\end{array}$ & $\begin{array}{l}191 \\
167\end{array}$ & $\begin{array}{l}41.9(80) \\
40.7(68)\end{array}$ & $\begin{array}{c}1 \\
1.32(0.51-3.44)\end{array}$ \\
\hline $\begin{array}{l}\text { No menstrual } \\
\text { migraine }\end{array}$ & $\begin{array}{l}\text { Non-menstrual attack } \\
\text { Menstrual attack } \\
\text { Multiple-agents }\end{array}$ & $\begin{array}{l}58 \\
19\end{array}$ & $\begin{array}{c}8.6(5) \\
10.5(2)\end{array}$ & $\begin{array}{l}0.12(0.01-1.74) \\
0.24(0.01-6.20)\end{array}$ \\
\hline $\begin{array}{l}\text { Menstrual } \\
\text { migraine }\end{array}$ & $\begin{array}{l}\text { Non-menstrual attack-ref } \\
\text { Menstrual attack }\end{array}$ & $\begin{array}{l}191 \\
167\end{array}$ & $\begin{array}{l}31.4(60) \\
41.9(70)\end{array}$ & $\begin{array}{c}1 \\
2.10(1.05-4.23)^{*}\end{array}$ \\
\hline $\begin{array}{l}\text { No menstrual } \\
\text { migraine }\end{array}$ & $\begin{array}{l}\text { Non-menstrual attack } \\
\text { Menstrual attack }\end{array}$ & $\begin{array}{l}58 \\
19\end{array}$ & $\begin{array}{l}20.7(12) \\
26.3(5)\end{array}$ & $\begin{array}{l}0.71(0.17-2.94) \\
1.30(0.21-8.21)\end{array}$ \\
\hline Diagnosis & $\begin{array}{l}\text { Continuous variables }{ }^{2} \\
\text { Number of doses per attack }\end{array}$ & n & mean (SD) & Coefficient $(99 \% \mathrm{CI})$ \\
\hline $\begin{array}{l}\text { Menstrual } \\
\text { migraine }\end{array}$ & $\begin{array}{l}\text { Non-menstrual attack-ref } \\
\text { Menstrual attack }\end{array}$ & $\begin{array}{l}189 \\
167\end{array}$ & $\begin{array}{l}2.34(2.68) \\
3.62(4.32\end{array}$ & $\begin{array}{c}0 \\
1.37(0.50-2.24)^{*}\end{array}$ \\
\hline $\begin{array}{l}\text { No menstrual } \\
\text { migraine }\end{array}$ & $\begin{array}{l}\text { Non-menstrual attack } \\
\text { Menstrual attack }\end{array}$ & $\begin{array}{l}57 \\
19\end{array}$ & $\begin{array}{l}2.14(2.97) \\
2.05(3.41)\end{array}$ & $\begin{array}{l}0.16(-1.61-1.93) \\
0.02(-2.31-2.36)\end{array}$ \\
\hline $\begin{array}{l}{ }^{1} \text { Linear mixed } n \\
\text { random interce } \\
\text { deviation. OR= } \\
\text { agents: combin }\end{array}$ & $\begin{array}{l}\text { el with random intercept (SAS M } \\
\text { AS GLIMMIX). }{ }^{*} p<0.01 . n=\text { numb } \\
\text { satio. } \mathrm{Cl}=\text { confidence interval. } N \\
\text { n of two or more types of drug ( }\end{array}$ & $\begin{array}{l}\text { ogisti } \\
\text { cks w } \\
\text { n-ste } \\
\text { ns an }\end{array}$ & $\begin{array}{l}\text { ression for hie } \\
\text { at missing valu } \\
\text { I anti-inflamm } \\
\text { AIDs). }\end{array}$ & $\begin{array}{l}\text { Srchical data with } \\
\text { s. } \mathrm{SD}=\text { standard } \\
\text { tory drugs. Multiple }\end{array}$ \\
\hline
\end{tabular}




\section{References}

1. Vetvik KG, Macgregor EA, Lundqvist $\mathrm{C}$, et al. Prevalence of menstrual migraine: A populationbased study. Cephalalgia. 2014;34:280-8.

2. Russell MB, Rasmussen BK, Fenger K, et al. Migraine without aura and migraine with aura are distinct clinical entities: a study of four hundred and eighty-four male and female migraineurs from the general population. Cephalalgia. 1996;16:239-45.

3. Headache Classification Subcommittee of the International Headache Society. The International Classification of Headache Disorders, 3rd edition (beta version). Cephalalgia. 2013;33:629-808.

4. Headache Classification Subcommittee of the International Headache Society. The International Classification of Headache Disorders: 2nd edition. Cephalalgia. 2004;24 Suppl 1:9-160.

5. Pinkerman B, Holroyd K. Menstrual and nonmenstrual migraines differ in women with menstrually-related migraine. Cephalalgia. 2010;30:1187-94.

6. Granella F, Sances G, Allais G, et al. Characteristics of menstrual and nonmenstrual attacks in women with menstrually related migraine referred to headache centres. Cephalalgia. 2004;24:70716.

7. MacGregor EA, Frith A, Ellis J, et al. Incidence of migraine relative to menstrual cycle phases of rising and falling estrogen. Neurology. 2006;67:2154-8.

8. MacGregor EA, Victor TW, Hu X, et al. Characteristics of menstrual vs nonmenstrual migraine: a post hoc, within-woman analysis of the usual-care phase of a nonrandomized menstrual migraine clinical trial. Headache. 2010;50:528-38.

9. Couturier EG, Bomhof MA, Neven AK, et al. Menstrual migraine in a representative Dutch population sample: prevalence, disability and treatment. Cephalalgia. 2003;23:302-8.

10. Stewart WF, Lipton RB, Chee E, et al. Menstrual cycle and headache in a population sample of migraineurs. Neurology. 2000;55:1517-23.

11. Diamond ML, Cady RK, Mao L, et al. Characteristics of migraine attacks and responses to almotriptan treatment: a comparison of menstrually related and nonmenstrually related migraines. Headache. 2008;48:248-58.

12. Silberstein SD, Massiou H, McCarroll KA, et al. Further evaluation of rizatriptan in menstrual migraine: retrospective analysis of long-term data. Headache. 2002;42:917-23.

13. Vetvik KG, MacGregor EA, Lundqvist C, et al. A clinical interview versus prospective headache diaries in the diagnosis of menstrual migraine without aura. Cephalalgia. 2014.

14. Tfelt-Hansen P, Pascual J, Ramadan N, et al. Guidelines for controlled trials of drugs in migraine: third edition. A guide for investigators. Cephalalgia. 2012;32:6-38.

15. Mannix LK, Loder E, Nett R, et al. Rizatriptan for the acute treatment of ICHD-II proposed menstrual migraine: two prospective, randomized, placebo-controlled, double-blind studies.

Cephalalgia. 2007; 27:414-21.

16. Loder E, Silberstein SD, Abu-Shakra S, et al. Efficacy and tolerability of oral zolmitriptan in menstrually associated migraine: a randomized, prospective, parallel-group, double-blind, placebocontrolled study. Headache. 2004;44:120-30.

17. Rasmussen BK, Olesen J. Migraine with aura and migraine without aura: an epidemiological study. Cephalalgia. 1992;12:221-8; discussion 186.

18. Russell MB, Iversen $\mathrm{HK}$, Olesen J. Improved description of the migraine aura by a diagnostic aura diary. Cephalalgia. 1994;14:107-17. 